\title{
REGISTROS SONOROS DO “FOLCLORE” DE ALTER DO CHÃO: propriedade intelectual e patrimônio imaterial na festa do Çairé
}

\section{SOUND RECORDINGS FROM THE FOLKLORE OF ALTER DO CHÃO. Intellectual property and intangible heritage at the Çairé festivities}

\author{
Luciana Carvalho*
}

\begin{abstract}
Resumo
O artigo aborda o processo de execução de registros sonoros para a confecção de um CD de músicas consideradas como folclore de Alter do Chão, Santarém/PA, em 2013. Tal ação, concebida como uma medida de salvaguarda e difusão cultural, fez parte do Inventário de Referências Culturais da Festa do Sairé, realizado em parceria com o Instituto do Patrimônio Histórico e Artístico Nacional para atender a uma demanda de grupos produtores dessa celebração, promovida anualmente em setembro. Nos termos de Gluckman (2010), a produção da peça é tomada como uma situação social privilegiada para a encenação das relações sociais entre festeiros, devotos, foliões e coordenadores da festa do Çairé, bem como para a expressão de suas concepções acerca de noções de autoria e propriedade intelectual. Cada etapa de confecção do CD apresenta-se como oportunidade para o exercício antropológico de análise de relações sociais caracterizadas por hierarquias, alianças e divergências entre os diversos responsáveis por uma festa emblemática da região oeste do Pará. Ademais, permite contemplar perspectivas entrecruzadas dos diversos atores sobre os institutos de propriedade intelectual envolvidos em uma proposta de documentação e difusão de patrimônio cultural imaterial.
\end{abstract}

Palavras-chave: Festa do Çairé. Registros sonoros. Patrimônio imaterial. Propriedade intelectual.

\begin{abstract}
This article analyzes the production of a Compact Disk in 2013 with musical recordings from the popular culture of Alter do Chão at the municipality of Santarém, state of Pará, Brazil. As a cultural safeguard and dissemination measure, this recording process became part of the Inventory of Cultural References of the Sairé Festivities in Alter do Chão. It was carried out in partnership with the Brazilian Institute for Historical and Artistic Heritage to meet a demand presented by the groups that organize the Çairé celebrations, held in september. In line with Gluckman (1958), this process is seen a privileged opportunity for the enactment of social relations among the attendees, devotees, revelers and organizers of the Çairé festivities, and for the expression of their views regarding authorship and intellectual property. Each stage in the production of this CD becomes, therefore, an opportunity of anthropologically analyzing the local social relations, including the particular hierarchies, alliances and divergences among the leading actors of this emblematic festival from the west of Pará. It also allows observing the interconnected perspectives of the actors of the festival regarding the intellectual property institutes involved in this proposal of documenting and disseminating the local intangible cultural heritage.
\end{abstract}

Keywords: Festa do Çairé ("Çairé Festival” in Alter do Chão, Pará, Brazil). Sound and music recordings. Intangible heritage. Intellectual property.

\footnotetext{
* Doutora em Antropologia; professora do Instituto de Ciências da Sociedade da Universidade Federal do Oeste do Pará (ICS/Ufopa). E-mail: lu_gcarvalho@yahoo.com.br
} 


\section{Introdução}

A festa do Çairé é usualmente referida na literatura especializada e no senso comum dos moradores de Santarém/PA como uma herança deixada pelos índios boraris catequizados na missão jesuítica de Nossa Senhora da Purificação, implantada em 1661 na margem direita do rio Tapajós, onde hoje está o distrito balneário de Alter do Chão (FERREIRA, G., 2005; FERREIRA, E., 2008; LIMA, 2013; FIGUEIRA, 2014). Realizada há mais de 300 anos, ela é representada como uma das mais tradicionais celebrações mescladas de ritos indígenas e do catolicismo popular na Amazônia, o "caso mais interessante de festas e danças originadas no processo da catequese pelo encontro das duas culturas" (CANDIDO, 2012, p. 49). Contudo, tendo passado por significativas mudanças estruturais ao longo dos séculos, a festa do Çairé não pode ser compreendida como simples continuidade do passado ou imanência da tradição. Afinal, têm variado, entre outros elementos, agentes rituais, personagens, datas e locais de realização, santos associados, ritos festivos e a própria grafia do nome da celebração -- ora Çairé, ora Sairé. ${ }^{1}$

A própria narrativa convencional da trajetória da festa a tem dividido em quatro etapas correspondentes a processos indutores de mudanças -- colonização, proibição, retomada e espetacularização. Resumidamente, ela informa que: se, na colonização, a catequese dos indígenas fomentou sincretismos entre ritos nativos e elementos católicos, em um Çairé misto de canto e procissão em homenagem a Nossa Senhora da Saúde, nos anos 1940, os párocos viriam a proibir a realização do festejo porque a ele se associavam práticas que não poderiam ser toleradas pela Igreja da época, a exemplo de danças e do consumo de bebidas como o tarubá. ${ }^{2}$ Já nos anos 1970, a retomada da festa foi operada por um grupo de moradores de Alter do Chão que, com aval dos párocos e em data distinta da festa da Virgem, mas em homenagem ao Divino Espírito Santo, recriou ritos do Çairé com fragmentos de memórias individuais e práticas identificadas como parte do folclore local. Por fim, o processo de espetacularização da festa se delineou a partir dos anos 1990, quando ela incluiu em sua programação a disputa entre

\footnotetext{
1 Justificativas linguísticas, históricas, étnicas, políticas e afetivas são acionadas pelos defensores das diferentes formas escritas. Em suma, argumenta-se que a adoção da grafia Çairé, supostamente proveniente do nheengatu (da saudação Çai e erélÇã-yerê) é mais condizente com as origens indígenas da festa -- e tende a ser preferencial no contexto atual de movimentos de afirmação étnica dos Borari, que envolvem também disputas territoriais em Alter do Chão e outras localidades de Santarém. Já a grafia Sairé, em obediência à norma da língua portuguesa, teria o objetivo de ampliar a divulgação da festa em circuitos turísticos e oficiais de cultura. A cada ano -- e a cada troca de administração municipal -- o debate se renova, mas grande parte dos pesquisadores da festa e sujeitos nela envolvidos admitem ambas as grafias. Por esse motivo, optou-se por manter a forma escrita usada por cada autor em citações diretas ou indiretas, mas por adotar a grafia Çairé nas formulações deste artigo, pois é a que consta no material de difusão dos registros sonoros resultantes do projeto Inventário de Referências Culturais da Festa do Sairé. Observa-se, ainda, que na época de concepção do projeto de inventário, os próprios representantes da festa escreveram Sairé nos documentos associados a ele. Por esse motivo, as referências ao inventário são grafadas com $S$.
}

2 Bebida de teor alcóolico, feita a partir da fermentação da mandioca, regularmente consumida nos festejos indígenas e ribeirinhos de Santarém e adjacências. Segundo Barbosa Rodrigues (1890, p. 280), era a "alma da festa". 
duas agremiações de botos (grupos folclóricos) que, ao estilo dos bois-bumbás de Parintins/ AM, se apresentam em uma espécie de arena. ${ }^{3}$

Conquanto essa narrativa apresente limitações, ${ }^{4}$ ela revela continuidades e rupturas na festa, pondo em relevo sucessivas hibridizações e reconfigurações que parecem resultar de um "esforço constante de recriação consciente das tradições festivas locais" (CARVALHO, 2016a, p. 251). Como resultado dos processos narrados, a festa do Çairé realizada todo mês de setembro em Alter do Chão constitui um exemplo claro do hibridismo que caracteriza muitas expressões culturais na Amazônia contemporânea (BRAGA, 2007; NOGUEIRA, 2008; COSTA, 2013). Destacando-se na cena cultural regional e adquirindo crescente visibilidade em contextos mais abrangentes, ela associa e articula, em múltiplos planos expressivos, ritos católicos com formas tradicionais e contemporâneas de expressão oral, musical, dramática e coreográfica, frequentemente designadas como folclóricas, mas também inspiradas em espetáculos dirigidos para grandes públicos. ${ }^{5}$

Enquanto a festa transita entre a memória e a inovação, sujeitos envolvidos em sua produção mostram-se apreensivos quanto ao futuro do Çairé. Em defesa do que consideram tradições inalienáveis, acionam narrativas de origem e performances que enfatizam a antiguidade, a riqueza expressiva e a importância da celebração na formação da identidade cultural regional. Acionam, também, instrumentos instituídos de proteção ao patrimônio cultural a fim de garantir a continuidade de certas tradições, inaugurando na trajetória da festa uma etapa que pode ser caracterizada como patrimonialização -- um processo complexo que, paradoxalmente, pode contribuir para novas mudanças no Çairé.

É nesse contexto que se situam o relato da experiência de inventário da festa do Çairé e as reflexões acerca do processo de execução de registros sonoros com vistas à produção de um $\mathrm{CD}$ de músicas tidas como folclore de Alter do Chão. Antes de comentar tal processo, porém, no próximo tópico serão abordadas algumas questões conceituais e metodológicas do Inventário Nacional de Referências Culturais (INRC), que é adotado pelo Instituto do Patrimônio Histórico e Artístico Nacional (Iphan) para identificação e documentação de bens culturais imateriais. Considerando especificamente o Inventário de Referências Culturais da Festa do Sairé (INRCSairé), pretende-se expor, ainda que minimamente, as condições de realização dos registros sonoros que são objeto deste texto. No item seguinte, o relato se volta para a emergência de um

\footnotetext{
3 A semelhança com o festival amazonense estudado por Cavalcanti (2000), Braga (2007); Nogueira (2013), tem sido objeto de discussões e críticas locais acerca da identidade própria do Çairé. Alguns usam o termo Boiré para remeter a essa semelhança.

4 Considerando os limites desta publicação, é inviável aprofundar o debate sobre a trajetória da festa. Para tanto, ver Carvalho (2016a; 2016b).

5 Destaco que outros festejos do Çairé, já extintos, foram registradas no Amapá, no Amazonas (PEREIRA, 1989; BOYER, 2008) e nos municípios paraenses de Belém (RODRIGUES, 2009) e Monte Alegre (VERÍSSIMO, 1887). Talvez, a continuidade da festa em Alter do Chão se deva justamente a essa "capacidade de se transformar e amalgamar referências simbólicas heterogêneas” (CARVALHO, 2016b, p. 23).
} 
conflito entre participantes da festa do Çairé e a equipe executora do inventário, tendo como pano de fundo os direitos autorais relativos ao CD. Tomando a gravação dessa peça como um evento dramático e uma situação social privilegiada para a observação das relações complexas que existem entre os atores envolvidos na produção, vislumbram-se suas perspectivas díspares sobre os institutos de propriedade intelectual e patrimônio imaterial. À guisa de conclusão, alguns comentários sobre a experiência analisada pretendem contribuir para a crítica das atuais políticas de patrimonialização.

\title{
A produção de registros sonoros no CD de músicas do INRC-Sairé
}

O projeto que deu origem aos registros sonoros em questão apoiou-se no Decreto $\mathrm{n}^{\mathrm{o}}$ 3.551/2000, que instituiu o Registro de Bens Culturais de Natureza Imaterial como patrimônio cultural do Brasil -- ato de natureza declaratória -- e o Inventário Nacional de Referências Culturais como metodologia aplicável a tais bens. Desenvolvida pelo antropólogo Antônio Augusto Arantes em colaboração com técnicos do Iphan, essa metodologia visou a preencher uma lacuna na instituição, que até então se servia de inventários como os de bens móveis e integrados e de bens imóveis em sítios urbanos, os quais não atendiam às demandas de produção e sistematização de conhecimentos para implementar o que fora previsto no Decreto $\mathrm{n}^{\circ} 3.551$. Segundo Arantes,

\begin{abstract}
esses formulários continham perguntas relativas a características demográficas da população residente em sítios inventariados e aos seus modos de vida. Mas eles não respondiam às questões decorrentes do Decreto 3551. Para integrar levantamentos relativos ao patrimônio material e imaterial não bastava simplesmente agregar informações de natureza sociocultural aos instrumentos de inventário arquitetônico e urbanístico existentes. Era necessário criar outros e, particularmente, passar a trabalhar com o conceito de 'lugar', que articula as dimensões tangível e intangível dos sítios protegidos (MORAIS; RAMASSOTE; ARANTES, 2015, p. 233).
\end{abstract}

Baseada em conceitos antropológicos absorvidos na Constituição Federal de 1988, essa metodologia pretende orientar a pesquisa e sistematizar informações sobre bens que tenham o valor de referências culturais ${ }^{6}$ para grupos formadores da sociedade brasileira, conforme os territórios de sua ocorrência, designados no INRC como sítios e localidades. ${ }^{7}$

Em uma perspectiva que sublinha a dimensão processual da cultura, os bens a que se refere o INRC são concebidos como "produtos históricos dinâmicos e mutáveis" e não

\footnotetext{
6 De acordo com o Manual de Aplicação do INRC, "falar em referências culturais [...] significa, pois, dirigir o olhar para representações que configuram uma 'identidade' da região para seus habitantes, e que remetem à paisagem, às edificações e objetos, aos 'fazeres' e 'saberes', às crenças, hábitos, etc.' (IPHAN, 2000, p. 14).

7 Sítios e localidades são delimitados conforme diferentes critérios, não necessariamente geográficos, e "correspondem à implantação de modos de vida, à percepção de fronteiras, à elaboração de regras de conduta e criação de valores" (IPHAN, 2000, p. 33).
} 
“configurações fixas e cristalizadas". A finalidade de um inventário de bens culturais de natureza imaterial, então, é captar os sentidos e valores "enraizados nas práticas sociais, que ademais de intangíveis ou imateriais, muitas vezes não chegam a ser explicitados ou nem mesmo afloram à consciência dos atores sociais" (IPHAN, 2000, p. 29). Todavia, a metodologia recomenda que se parta das "dimensões concretamente apreensíveis da cultura" (IPHAN, 2000, p. 30), indo dos comportamentos concretos à "atitude mental que neles se expressa" (Malinowski, 1978, p. 30-31). Para acessar o sentido imaterial, portanto, o INRC foca em elementos passíveis de materialização ${ }^{8}$ e menção em formulários padronizados para inserção de informações relativas a saberes, lugares, formas de expressão, celebrações e edificações. ${ }^{9}$

Apesar de ser utilizado principalmente pelo próprio Iphan, mediante autorização do órgão e anuência dos detentores ${ }^{10}$ dos bens que se pretende inventariar, o INRC pode ser usado por outras instituições, públicas ou privadas, a fim de subsidiar processos de registro, diagnósticos do patrimônio cultural brasileiro e projeção de ações que visem à sua salvaguarda. No caso do INRC-Sairé, Carvalho (2016b, p. 26-27) informa que, em agosto de 2011:

\begin{abstract}
representantes legais de grupos produtores da festa do Çairé apresentaram ao Programa de Extensão Patrimônio Cultural na Amazônia (Pepca), da Universidade Federal do Oeste do Pará (Ufopa), a demanda de apoio técnico para a formulação de um possível pedido de registro dessa celebração junto ao Iphan. Entendendo que a festa do Sairé de Alter do Chão apresenta um verdadeiro mosaico de bens passíveis de ações de patrimonialização, mas que é preciso identificar exatamente o que a comunidade pretende registrar, foi proposta aos grupos e ao Iphan a realização preliminar do Inventário de Referências Culturais do Sairé [para] produzir conhecimento sobre a festa e compreender seus significados para a comunidade, a fim de poder formular e qualificar o objeto de um eventual pedido de registro ao Iphan.
\end{abstract}

A proposta do inventário e a formulação do projeto foram debatidas pela equipe do Pepca/Ufopa em uma série de reuniões com representantes de diferentes grupos de festeiros. Com efeito, são vários os sujeitos que cooperam para a realização do Çairé, ocupando-se diferentes aspectos e atividades da programação festiva: dançarinos, artesãos, artistas plásticos, cozinheiros, foliões, rezadeiras, músicos e muitos outros colaboradores. Em regra, esses festeiros fazem parte de grupos formais e informais que se organizam segundo hierarquias próprias, conforme os vários tipos de competências requeridas na produção do evento: rituais, técnicas, administrativas, burocráticas e performáticas, entre outras.

8 O manual do Iphan (2000, p. 30) cita, especificamente, "documentos escritos, audiovisuais, objetos, bem como depoimentos e narrativas orais".

9 Com exceção da última, essas categorias correspondem aos quatro livros do patrimônio imaterial do Iphan: Saberes, Lugares, Formas de Expressão e Celebrações.

10 O manual refere como detentores "os sujeitos diretamente envolvidos com a dinâmica da produção, circulação e consumo dos bens culturais", sublinhando "as implicações políticas dessa perspectiva [e] seus limites em situações concretas, quando até o termo 'comunidade' pode servir para encobrir interesses de grupos locais mais poderosos, de autoridades políticas, etc." (IPHAN, 2000, p. 19). 
Nas reuniões de preparação do projeto, os festeiros se fizeram representar por membros da Comissão Organizadora e Coordenadora do Festival Folclórico do Sairé (vulgarmente chamada Coordenação da Festa), do Boto Tucuxi, do Boto Cor de Rosa, da Administração Distrital de Alter do Chão e do Conselho Comunitário de Alter do Chão. Na execução das ações projetadas, à Coordenação da Festa coube, pelo menos no plano formal, a função de articular e conduzir as tomadas de decisão junto aos grupos de foliões, músicos e rezadeiras, que foram os participantes mais ativos do projeto. O projeto lidou, então, com duas esferas de representação -- uma baseada na hierarquia administrativa e outra na hierarquia ritual -- que, eventualmente, divergiriam.

No geral, havia entre os representantes dos festeiros expectativas de que o inventário e um eventual registro da festa do Çairé reforçasse expressões consideradas estruturantes e tradicionais da celebração, que estariam perdendo espaço para outras expressões agregadas à celebração nas últimas décadas. Logo, em função das demandas locais, o projeto também assumiu o objetivo de aliar ao inventário ações de salvaguarda. ${ }^{11}$ Em vista desse propósito, os representantes dos festeiros elegeram práticas musicais associadas à festa como objeto de atenção prioritário, propondo a realização de oficinas de repasse de saberes e a gravação de um CD.

O projeto foi apresentado à Superintendência do Iphan no Pará, que aceitou custear materiais de consumo, serviços de terceiros e bolsas de pesquisa e extensão para estudantes de graduação. Em contrapartida, a Ufopa disponibilizou recursos, instalações, equipamentos e serviços de professores pesquisadores do quadro institucional. Assim foi estabelecida a parceria entre as duas instituições, na forma de um Termo de Cooperação Técnica. Já por meio de um Termo de Compromisso, o Iphan concedeu à Ufopa o direito de uso da metodologia do INRC, observando-se as obrigações estipuladas no art. $5^{\circ}$ da Instrução Normativa do Iphan no 001/2009.

I - Colher todas as autorizações que permitam ao Iphan o uso de imagens, sons e falas registrados durante o processo de inventário;

II - Ceder gratuitamente ao Iphan todos os direitos autorais patrimoniais, incluídos os direitos de uso, disposição e reprodução, sob qualquer forma, para promoção, divulgação e comercialização sem fins lucrativos dos produtos e subprodutos resultantes do trabalho de inventário, resguardado os direitos morais do autor, neles compreendido a identificação de autoria (IPHAN, 2009, p. 2).

Observe-se que, antes mesmo de realizar pesquisas e/ou registros, a instituição executora do inventário teve de ceder ao Iphan todos os direitos autorais patrimoniais relativos a produtos

11 O Plano de Salvaguarda é um instrumento adotado pelo Iphan para apoiar e fomentar bens culturais de natureza imaterial registrados como Patrimônio Cultural Brasileiro. Concebido como um planejamento estratégico a partir do diagnóstico efetuado no processo de registro, ele pressupõe a interlocução direta do Iphan com os grupos interessados na formulação e execução de ações de valorização dos produtores e detentores do bem cultural registrado, a fim de garantir as melhores condições de sua produção e reprodução. 
e subprodutos do INRC-Sairé, além de se comprometer a colher as autorizações de uso dos mesmos junto aos participantes do projeto, adotando para isso um Termo de Autorização de Uso de Voz, Imagem e Informações disponibilizado pelo Iphan. Como essas obrigações são condições imprescindíveis para o licenciamento do uso da metodologia, nenhuma das partes atentou para o fato de que, com a produção do CD de músicas, o INRC-Sairé criaria uma disputa por direitos, na medida em que deixara de considerar as expectativas de direitos autorais patrimoniais de compositores, músicos e intérpretes que viriam a ser envolvidos na produção.

O projeto foi iniciado em julho de 2012, retomando-se o contato com os membros de grupos organizados e instituições que haviam participado dos debates anteriores à proposição do projeto ao Iphan. Com a anuência deles, a pesquisa de campo começou, como de praxe, pelos contatos e entrevistas com os sujeitos mais antigos e os personagens mais importantes da festa, entre os quais os foliões que cantam e tocam as músicas que deveriam compor o referido CD.

Ocorre que, na primeira tentativa de contato com eles, durante um ensaio, os bolsistas de pesquisa e extensão foram desautorizados a realizar as atividades programadas, sob a alegação de que o grupo jamais fora informado ou consultado sobre o projeto de inventário. Comunicados da anuência concedida por aquela coordenação, os foliões reclamaram a competência das diferentes autoridades no Çairé: "Aqui na folia tem um capitão e tem os alferes, e primeiro tem que falar com eles". Logo, foi marcada uma reunião entre a coordenação do projeto e o grupo de foliões, durante a qual foram prestados os esclarecimentos sobre o inventário.

De acordo com a memória escrita da reunião, os foliões estavam, de fato, "muito desinformados do processo, ${ }^{12}$ embora representantes da Coordenação da Festa, que se disseram ligados a eles, tivessem participado de todas as etapas de concepção e encaminhamento do projeto" (UFOPA, 2012, p. 1).

[A coordenadora do projeto] explicou de que se trata no Inventário e fez o histórico de todas as negociações com a Coordenação da Festa e outras instâncias representativas, até o presente. Entregou comunicado formal do projeto com cópias dos termos de anuência assinados por aquelas instâncias [...]. Frisou que a pesquisa, o inventário, é um trabalho técnico. Porém, esclareceu que, num possível pedido de registro do bem como patrimônio cultural, deverá haver uma negociação intensa dentro dos grupos festeiros e entre eles para que se chegue a um acordo sobre o que constitui seu patrimônio cultural. Ou seja, o que deve ser efetivamente encaminhado como pedido de registro. Frisou que essa decisão, embora possa se servir dos conhecimentos técnicos produzidos no inventário, recai principalmente sobre critérios políticos a serem trabalhados entre e pelos grupos (UFOPA, 2012, p. 1).

12 Alguns foliões também mencionaram ter desconfiança e temores de que o projeto visasse os grupos de botos como objeto de patrimonialização, deixando entrever que, em seu entendimento, o festival dos botos não é parte integrante do Çairé, embora ocorra no período da festa (UFOPA, 2012). Esse entendimento é compartilhado por sujeitos para quem o Çairé se delimita na prática de ritos de fé tradicionais, os quais defendem a mudança da data de realização do festival dos botos a fim de não ofuscar a natureza da festa. Embora essa proposta seja objeto de polêmica a cada ano, tudo indica que a atração introduzida na programação festiva no final da década de 1990 está tão fortemente vinculada ao Çairé que envolve, inclusive, personagens tradicionais da festa e seus familiares. 
O mal-entendido acerca dos limites das anuências obtidas preliminarmente foi superado, e as devidas desculpas foram apresentadas ao grupo, que logo aquiesceu com a continuidade do trabalho. Esse episódio, embora embaraçoso, foi altamente instrutivo sobre as "unidades concretas de comportamento organizado" na festa do Çairé e os limites da identificação dos legítimos detentores dos bens culturais em situações concretas. O ocorrido revelou a existência de autoridades paralelas que operam de acordo com regras e hierarquias próprias, sendo que, no caso, a autoridade formal da Coordenação da Festa, atestada nos documentos de constituição da entidade,${ }^{13}$ chocou-se com a autoridade ritual dos foliões, sobretudo aqueles investidos nos cargos de capitão e alferes. ${ }^{14}$ Por fim, ainda demonstrou a insuficiência dos instrumentos formais de anuência prévia exigidos pelo Iphan para a realização de inventários, ${ }^{15}$ na medida em que os próprios grupos, internamente, disputam direitos e questionam limites da delegação e representação.

$\mathrm{Na}$ continuação das atividades do projeto, as relações com os foliões foram consolidadas e, no início de 2013, foram realizadas as discussões preliminares sobre a produção do CD de músicas. Acordou-se a realização imediata de uma oficina visando ao repasse de saberes relativos às práticas musicais do Çairé, que seria ministrada por dois antigos foliões membros do grupo Espanta-Cão. ${ }^{16}$ Ao término da oficina, eles elencariam o repertório a ser gravado.

Os encontros [...] foram comandados pelos músicos locais participantes do grupo da Folia e do Espanta-Cão do Sairé, selecionados e acionados pela Coordenação da Festa. O público alvo foi composto de aprendizes em estágio inicial ou intermediário de conhecimento das músicas do Sairé e da execução dos instrumentos em foco na oficina: violinos, cavaquinhos, pandeiros, tamborim, caixas, maracás, xeques-xeques, reques-reques. Os aprendizes foram jovens, adultos e idosos da própria Vila de Alter do Chão, que já mantinham alguma relação com o grupo musical executor da festa. Nos encontros o programa da oficina foi desenvolvido da seguinte forma: primeiramente, cada instrumento musical foi apresentado -- sua história, formas de confecção, materiais usados, tipos de sonoridade, importância no conjunto do Sairé; em seguida foi treinada a execução dos instrumentos [...]; por fim, foi definido um repertório para treinos e para posterior gravação do CD musical do projeto (UFOPA, 2013, p. 6).

13 A Coordenação da Festa tem como funções representar, de maneira geral, todos os segmentos envolvidos na produção do Çairé, bem como gerir os recursos humanos e materiais necessários à realização do evento.

14 Tenho sustentado que os "festeiros provavelmente atualizam representações nativas das hierarquias reais e militares atualizam representações nativas das hierarquias reais e militares dos colonizadores, ao mesmo tempo que reencenam elementos próprios do meio e da vida local, configurando, assim, uma hierarquia festiva particular" (CARVALHO, 2016b, p. 72). Nessa hierarquia festiva destacam-se estes personagens: Capitão; Saraipora; Juiz e Juíza; Alferes; Moça-da-Fita; Troneira; Despenseira; Cozinheiros; Foliões; e Rezadeiras. Em respeito aos limites desta publicação, não comentarei sobre os personagens e suas funções. Para tanto, ver Carvalho (2016b).

15 De acordo com o artigo $3^{\circ}$ da IN no 001/2009 o Iphan exige que, para fins de licenciamento do uso da metodologia do INRC, a instituição executora do inventário apresente a "comprovação de que recebeu anuência das comunidades ou grupos a serem inventariados".

16 Segundo Mascarenhas (2015), o Espanta-Cão foi formado por antigos moradores de Alter do Chão que aprenderam música informalmente e tocavam instrumentos de percussão, corda e sopro. Nos anos 1980, o grupo foi convidado para fazer o acompanhamento musical de algumas danças folclóricas, e, desde então, atua na festa do Çairé. Entre seus componentes, todos são também foliões da festa, apesar de que nem todos os foliões fazem parte do grupo. Segundo narrativas locais, seu nome "alude à cruz formada pelo arco de madeira ao friccionar as cordas do violino, cujo toque é supostamente responsável por espantar os maus espíritos e abrir os caminhos para a festa” (CARVALHO, 2016b, p. 84). 
Definidas as faixas musicais que comporiam o CD, os mestres selecionaram e organizaram o grupo de músicos e intérpretes que participariam da gravação. Em cerca dois meses, deram início à segunda etapa da oficina para aprimorar a performance do grupo. Sob comando de Cleuton Sardinha, representante da Coordenação da Festa, e Mestre Camargo, capitão dos foliões, foram realizados cerca de vinte encontros, dos quais quinze se constituíram em ensaios. Deles participaram foliões, rezadeiras, coordenadores da festa e músicos em formação.

Os primeiros encontros ocorreram em residências de festeiros, mas, como despertaram o interesse de pessoas que queriam assistir aos ensaios e ouvir as músicas, passaram a ser realizados em um bar na área central de Alter do Chão, atraindo um público cada vez maior, assim como novos músicos que quiseram se integrar ao grupo. ${ }^{17}$ Para finalizar essa etapa, reuniões internas foram promovidas antes do agendamento da gravação, com o objetivo de acertar detalhes desse evento.

A gravação do CD, finalmente, foi realizada em julho de 2013, em uma residência em Alter do Chão, utilizando-se um estúdio portátil. À frente do trabalho esteve Eduardo Dias, que, além de poeta, compositor e cantor reconhecido no meio musical regional, tem conhecimentos e boas relações com os músicos do Çairé. Graças a isso, foram contornados problemas que serão narrados no próximo tópico, permitindo a conclusão da gravação.

Quinze faixas musicais foram gravadas: Marambiré, Hino de Alter do Chão, Quebra macaxeira, Desfeiteira, Magirona e alecrim, Pipira brasileira (Nossa simpatia), Cruzador Tupi (Do Rio Grande do Norte), Pipira brasileira (A brasileira), Cruzador Tupi (Depressa, marujo), Cruzador Tupi (Chegamos, companheiros), Lundum, Rouxinol (Entrada), Pot pourri (Manué, Berboleta, Baiano, São Benedito), Esterengo-tengo e Nossa viagem -- todas elas identificadas pelo grupo como parte do folclore de Alter do Chão. ${ }^{18}$ As duas primeiras têm Alter do Chão como tema, ressaltando suas belezas naturais em uma perspectiva romântica; umas são canções dos antigos cordões de pássaro que existiam na vila (facilmente identificáveis pela menção ao pássaro no título); outras são canções de trabalho (Quebra macaxeira) ou de brincadeiras de roda (Esterengo-tengo). Há, ainda, músicas instrumentais e composições de autoria desconhecida, mas já gravadas por cantoras como Inezita Barroso e Delora Bueno (São Benedito).

Além do $\mathrm{CD}$ e do próprio inventário, o INRC-Sairé gerou outros produtos de documentação e difusão cultural, os quais também seriam úteis para um eventual pedido de registro da festa: um livro, doze banners, um filme etnográfico e centenas de fotografias. Todavia, paradoxalmente, a conclusão do projeto em outubro de 2015 não trouxe avanços ao objetivo

17 Por meio dos ensaios abertos, o grupo adquiriu maior visibilidade em Santarém e passou a receber convites para apresentações fora da festa do Çairé e até mesmo do Pará. Segundo Mascarenhas (2015), o Espanta-Cão era formado por sete componentes, mas, após as atividades preparatórias para a gravação do CD, passou a ter treze integrantes.

18 Não cabe analisar o conteúdo das faixas gravadas neste artigo, mas entende-se que essa tarefa seja importante para melhor compreensão tanto do universo musical quanto da concepção de folclore que se difunde em Alter do Chão. 
inicial dos representantes da festa que provocaram a sua realização. Se, em 2011, eles almejavam conferir ao Çairé o título de patrimônio cultural do Brasil, quatro anos depois (e até o presente) já não se mobilizavam para isso.

\section{A emergência da propriedade intelectual}

A gravação do CD foi um episódio dramático do projeto -- e o mais tenso em toda sua execução --, pois instaurou um conflito aberto entre músicos e intérpretes, de um lado, e a equipe do INRC-Sairé, de outro. Porém, seguindo Victor Turner (1974), para quem o conflito é inerente à dinâmica da vida social, reconheço nele um evento ímpar capaz de promover uma mudança expressiva na forma de abordagem dos produtos do inventário por parte das instituições executoras, incluindo o próprio Iphan. Por outro lado, nos termos de Gluckman (2010), constituiu uma situação social privilegiada para a encenação das relações sociais entre festeiros, foliões e coordenadores da festa do Çairé, bem como para a expressão de suas concepções acerca de noções de autoria e propriedade intelectual -- o que é absolutamente rico para a pesquisa antropológica.

Especificamente, o conflito trouxe à tona uma inconsistência do regramento aplicado ao uso da metodologia do INRC, no que se refere à dimensão dos direitos autorais relativos aos registros executados durante o processo de inventário. ${ }^{19}$ De acordo com a IN no 001/2009 do Iphan, o instituto detém o direito de uso de todo e qualquer registro (voz, depoimento, imagem fixa ou em movimento) executado no INRC, por meio de uma autorização formal a ser colhida junto a cada indivíduo que venha a ser entrevistado, gravado, fotografado ou filmado no âmbito do inventário. Detém, igualmente, os direitos autorais patrimoniais, inclusive os direitos de uso, disposição e reprodução de todos os produtos e subprodutos que resultem do inventário, resguardando apenas os direitos morais do autor, como o direito à identificação de autoria. Foi justamente essa condição que deflagrou o conflito em torno do CD do INRC-Sairé.

Para entender a contenda, importa discernir que, na legislação brasileira, os direitos autorais possuem duas dimensões: a moral e a patrimonial. A primeira engloba direitos inalienáveis e irrenunciáveis do autor, entre os quais os de: reivindicar os créditos de autoria a qualquer tempo; decidir sobre o ineditismo da obra; assegurar sua integridade; modificá-la antes ou depois de utilizada; retirá-la de circulação; e ter acesso a exemplar único e raro da obra, quando se encontre legitimamente em poder de outrem a fim de preservar sua memória.

A segunda dimensão abrange direitos patrimoniais que podem ser transferidos ou cedidos a terceiros a título oneroso ou gratuito, conforme decisão do autor. A ele cabe o direito

19 A experiência do INRC dos Quilombos de Oriximiná, por mim coordenada, impôs ao Iphan lidar com outro aspecto do problema, na medida em que os quilombolas participantes das ações de pesquisa e documentação reivindicaram o pleno direito de uso dos registros produzidos no inventário, sobretudo os fotográficos. Uma negociação com o Iphan foi conduzida a fim de disponibilizar esses registros para uso das comunidades, mediante algumas regras. O caso merecerá considerações em outra oportunidade. 
exclusivo de utilizar, fruir e dispor da obra, dependendo de sua autorização prévia e expressa a utilização da mesma para fins de reprodução, edição, adaptação, inclusão em fonograma ou produção audiovisual, e distribuição, quando esta não for intrínseca ao contrato firmado com terceiros para uso ou exploração da obra. Ainda, assegura a Lei no 9.610/1998 que, em "qualquer modalidade de reprodução, a quantidade de exemplares será informada e controlada, cabendo a quem reproduzir a obra a responsabilidade de manter os registros que permitam, ao autor, a fiscalização do aproveitamento econômico da exploração”. A esse respeito, Belas (2004, p. 195) pondera que:

Em termos patrimoniais as comunidades têm dificuldades para reivindicar os benefícios e referentes à comercialização de suas expressões culturais, uma vez que, na maioria dos casos, não há indicação de origem. De outra forma, em relação aos direitos morais há uma preocupação com o prejuízo cultural, social e psicológico causado pela utilização não autorizada.

Evidentemente, não era objetivo do Iphan comercializar as músicas do Çairé, mas os festeiros envolvidos na produção do CD tinham essa expectativa, considerando a vitalidade do mercado de bens da cultura popular em um contexto histórico em que "a indústria do entretenimento se dirigiu para o exótico" (CARVALHO, 2004, p. 68) e criou esferas onde artistas populares negociam recursos com o Estado a partir do que poderíamos chamar de parâmetros do público, ou parâmetros sociais, de interesse comum” (CARVALHO, 2010, p. 58).

Ainda, vale frisar que, apesar de o Iphan reconhecer os direitos de propriedade intelectual dos produtores dos bens culturais inventariados ${ }^{20}$ e de sua IN $\mathrm{n}^{\circ} 001 / 2009$ incidir apenas na dimensão patrimonial dos direitos autorais, o instituto até então desconsiderou que os registros e produtos de um inventário podem ter diferentes naturezas e implicar distintas expectativas de direitos. Por exemplo, diferem significativamente os registros das músicas do Çairé obtidos por pesquisadores de campo durante entrevistas e eventos festivos -- em geral, por meio de gravadores digitais ou aplicativos de gravação de aparelhos de telefonia celular -- daqueles realizados por um profissional da música, em condições controladas e por meio de um estúdio portátil.

Na primeira situação os registros sonoros de caráter etnográfico, em geral de baixa qualidade, destinam-se prioritariamente ao uso da equipe executora do INRC para fins de compreensão do objeto pesquisado, bem como a integrar o acervo Iphan com finalidades de preservação de memória. Já na segunda, trata-se de uma produção de qualidade superior cujo objetivo expresso é a reprodução e distribuição de um CD em circuitos mais amplos. Logo, essa produção merece a proteção que a Lei $n^{\circ}$ 9.610/1998 confere às obras intelectuais enquanto

20 O modelo de Termo de Compromisso adotado pelo órgão a fim de autorizar o uso do INRC obriga a instituição executora a respeitar os direitos da propriedade intelectual dos produtores dos bens culturais em qualquer forma de uso do conhecimento produzido com a aplicação da referida metodologia. 
"criações do espírito, expressas por qualquer meio ou fixadas em qualquer suporte, tangível ou intangível".

Nesse sentido, o Termo de Autorização de Uso de Voz, Imagem e Informações recolhido no âmbito das ações de pesquisa e documentação do INRC mostrou-se, não só insuficiente, mas -- o que é mais grave -- inadequado à produção do CD. Em poucas e simples palavras, a situação pode ser assim exposta: i) para usar o INRC, a Ufopa cedeu ao Iphan, de antemão, todos os direitos de uso e reprodução dos registros e produtos do inventário, subentendido entre eles o CD de músicas; ii) a Ufopa se comprometeu a obter, de todos os indivíduos representados nos registros e produtos do INRC, a autorização de uso de voz, imagem e informações por meio do termo supracitado; iii) apesar do compromisso assumido no projeto, de produzir e distribuir o CD em questão, a Ufopa não recebera, da parte dos músicos, compositores e intérpretes, a anuência para tal. ${ }^{21}$

A medida adotada pela equipe da universidade, a partir de sugestão de um membro que é advogado e prestou assessoria jurídica ao projeto, foi a elaboração de um Termo de Anuência para Produção e Distribuição de CD de Músicas Tradicionais da Festa do Sairé, o qual deveria ser assinado por cada participante da gravação em favor da Ufopa. Os objetivos dessa medida, eram:

garantir os direitos institucionais de produção, distribuição e gestão da obra, com o intuito de: a) proteger a Ufopa na fase de produção; b) garantir à Ufopa o direito de distribuição para cumprimento das cotas institucionais e distribuição gratuita para escolas, bibliotecas, instituições de pesquisa, etc.; c) garantir o cumprimento das disposições relativas a direitos e propriedade dos registros e produtos, conforme Termo de Cooperação com o Iphan (UFOPA, 2013). ${ }^{22}$

Estando todos reunidos para dar início à gravação do $\mathrm{CD}$, juntamente com vias do Termo de Autorização de Uso de Voz, Imagem e Informações exigido pelo Iphan, cópias do Termo de Anuência em favor da Ufopa foram distribuídas. Conquanto o advogado que havia concebido o instrumento explicasse os motivos que levaram a equipe a lançar mão desse recurso, instaurouse rapidamente uma discussão acalorada entre os presentes, e não faltaram acusações à equipe da universidade. ${ }^{23}$ Finalmente, chegou-se ao acordo de realizar a gravação e não assinar nenhuma autorização de uso dos registros, nem em favor da Ufopa, nem em favor do Iphan.

21 A anuência obtida no início do projeto referia-se genericamente à sua realização, mas não especificava a autorização para a Ufopa atuar na produção e distribuição de uma obra sujeita à proteção pela legislação de direito autoral.

22 Restariam descobertos os eventuais direitos de autores das composições melódicas e letras a serem gravadas, problema esse que se mostrou irresolúvel, posto que, segundo os festeiros, os autores eram desconhecidos, falecidos ou inacessíveis.

23 A situação piorou quando, em ligação telefônica entre a coordenadora do projeto e o coordenador da festa, a primeira informou "não estar aî" (referindo-se a Santarém, seu local de residência) para tratar do assunto. A declaração foi entendida como absoluto descaso, como na expressão "não estar nem aí", quando, na verdade, a coordenadora informava que estava em Belém/PA, justamente em uma sequência de reuniões com técnicos do Iphan para tratar de projetos conjuntos em andamento. 
A gravação do $\mathrm{CD}$ foi bem-sucedida graças à interveniência do profissional responsável por ela, mas a proposta de a Ufopa ter direitos sobre obra -- dos quais necessitava a fim de poder transferi-los ao Iphan -- gerou tamanha insatisfação e desconfiança em músicos e membros da Coordenação da Festa, que um advogado acionado pelo grupo comunicou à equipe executora do INRC que recorreria ao procurador da República Felício Pontes ${ }^{24}$ para tomar providências junto à universidade.

Apesar dessa comunicação, em uma reunião realizada para debater o problema e propor possíveis soluções, as coordenações do projeto e da festa, junto com os músicos e intérpretes, pactuaram a busca de uma solução sui generis para o caso, envolvendo o Iphan, a Ufopa e a Comissão Organizadora e Coordenadora do Festival Folclórico do Sairé, que intencionava ter os direitos sobre a obra -- o que, na realidade, se alinha melhor com o objetivo declarado pelo Iphan de "reconhecer [aos detentores dos bens culturais] o estatuto de legítimos detentores não apenas de um 'saber-fazer', como também do destino de sua própria cultura” (IPHAN, 2000, p. 19).

De imediato a coordenação do projeto expediu consulta ao Iphan sobre como proceder a fim de passar à Coordenação da Festa os direitos de propriedade relativos à obra produzida, cabendo à Ufopa apenas os direitos de produção e distribuição da primeira tiragem, de mil exemplares, conforme previsto no projeto. Na oportunidade, foi sugerida ao Iphan a elaboração de um termo a ser assinado entre os três entes envolvidos na produção do CD: o Iphan, a Ufopa e a Coordenação da Festa.

Sendo a Coordenação da Festa a gestora do CD, deveria haver um termo tripartite sobre os compromissos que ela passaria a assumir perante o Iphan e a Ufopa. Nossa preocupação maior com posteriores tiragens feitas por governos, ONGs e terceiros, sob gestão da Coordenação, recai sobre o eventual não cumprimento dos créditos devidos a intérpretes e instituições envolvidas na produção do máster.

Vale ressaltar que o CD se compõe de músicas tradicionais, folclóricas, de autoria desconhecida na maioria das vezes. Apenas algumas letras e melodias têm autores conhecidos, sendo algumas já de domínio público.

Enfim, entendemos que temos o dever de orientar bem a Coordenação e preservar a Ufopa e o Iphan neste processo. Por ora, estamos suspendendo a obtenção de autorização para gestão da obra, e vamos solicitar apenas autorização para produzir a obra gratuitamente em sua primeira tiragem, de 1000 exemplares, sendo parte reservada para distribuir gratuitamente a instituições e parte para a própria coordenação da festa. Para tanto, precisamos saber logo quais são as cotas institucionais para o Iphan, a fim de apresentarmos aos músicos uma proposta de distribuição (Comunicação de correio eletrônico).

24 O procurador paraense, além de ter trabalhado durante anos em Santarém, é reconhecido pela atuação em defesa dos direitos e modos de vida dos povos tradicionais amazônicos. Nos últimos anos, foi recorrentemente mencionado em meios de comunicação de abrangência nacional e internacional em função de sua atuação no caso da Hidrelétrica de Belo Monte. 
Sem demora, o Iphan acatou a demanda dos produtores do Çairé e a proposta de elaboração de um termo tripartite que estipule os direitos e as obrigações de cada parte, assim como as relações entre elas. Uma minuta do termo foi elaborada em conjunto pela Ufopa e o instituto, aproveitando-se de trechos do termo de anuência que a universidade apresentara no dia da gravação, e submetida à apreciação da Coordenação da Festa e dos sujeitos que ela representa, no início de 2014.

A minuta do termo contém: i) um preâmbulo que contextualiza o INRC-Sairé e o CD como uma das ações desse projeto; ii) a descrição do CD e de sua finalidade de difusão cultural, inclusive cotas de distribuição gratuita para instituições públicas e para a Coordenação da Festa; iii) as condições sob as quais se concede à Ufopa a anuência para produzir e distribuir a primeira tiragem da peça; iv) cláusulas de propriedade intelectual e direitos compartilhados entre as três partes; v) compromissos da Coordenação da Festa e do grupo informal de músicos, aos quais se concedeu o direito de comercialização da peça.

Cientes. Das características do produto "CD de Músicas Tradicionais do Sairé"; Da vinculação do produto "CD de Músicas Tradicionais do Sairé" ao projeto INRC-Sairé, realizado pela Ufopa em parceria com o Iphan;

Dos objetivos do INRC-Sairé;

Do investimento de recursos públicos federais para realização do projeto INRC-Sairé e de todos os seus produtos,

A Comissão Organizadora e Coordenadora do Festival Folclórico do Sairé (Coordenação da Festa) e o grupo informal de músicos das folias e do Espanta Cão, concedem, pelo presente termo, sua anuência para a produção e a distribuição da tiragem de 1000 exemplares do "CD de Músicas Tradicionais do Sairé" pela Ufopa, no âmbito do INRC-Sairé.

Ao concederem sua anuência para a referida produção e distribuição da peça musical, a Coordenação da Festa e o grupo informal de músicos das folias e do Espanta Cão, autorizam a Ufopa, por intermédio do Programa de Extensão Patrimônio Cultural na Amazônia, a:

Proceder à execução dos serviços de gravação, mixagem e edição final das faixas de música do $\mathrm{CD}$, previamente selecionadas pelos músicos da festa;

Proceder aos serviços de confecção de arte gráfica e identidade visual das peças (rótulo, capa, encarte) que acompanham o $\mathrm{CD}$, os quais deverão ser previamente aprovados pela Coordenação da Festa e pelo grupo informal de músicos das folias e do Espanta Cão, no que tange a imagens de componentes e personagens da festa;

Proceder aos serviços de prensagem do CD com tiragem única de 1000 exemplares;

Contratar e pagar os profissionais necessários para realização dos serviços supracitados de acordo com procedimentos administrativos próprios da Ufopa, sem interferência por parte da Coordenação da Festa e do grupo informal de músicos, e sem nenhum tipo de ônus financeiro para esses dois grupos;

Proceder à distribuição da tiragem única de 1000 exemplares do CD de acordo com as cotas de: 100 unidades para o Iphan; 100 para a Ufopa; 300 para escolas públicas, bibliotecas, instituições de pesquisa no estado do Pará e fora dele; e 500 para a Coordenação da Festa (IPHAN; UFOPA, 2014, p. 2-3). 
A solução apresentada pacificou as relações entre as três partes envolvidas na produção do $\mathrm{CD}$ e garantiu condições de finalização do trabalho, que, foi intitulado Festa do Sairé de Alter do Chão. Apresentado em estojo duplo, junto com DVD do filme etnográfico sobre a festa, o CD foi acompanhado de um encarte com créditos de autoria e a transcrição das músicas gravadas -- outra tarefa que gerou conflitos, desta vez apenas entre os próprios músicos e intérpretes, e que merecerá considerações em outra oportunidade.$^{25}$ A recepção da peça entre os participantes do INRC-Sairé foi muito positiva, e declarações elogiosas ao material foram registradas em diferentes oportunidades.

\section{Considerações finais}

A experiência conflituosa de produção do $\mathrm{CD}$ de músicas associadas à festa do Çairé e ao folclore de Alter do Chão fez recordar uma situação vivenciada cerca de dez anos antes, quando Betinho, um brincante de bumba meu boi, me relatou um sonho no qual solicitava apoio para registrar em cartório uma performance que acabara de realizar.

Eh, Luciana! Eu queria mesmo falar contigo. É que eu tive um sonho com nós dois. E eu queria que tu me ajudasse. Eu sonhei o seguinte. Eu sonhei que nós [o Bumba-Meu-Boi da Fé em Deus] íamos fazer uma apresentação no Reviver, na Praia Grande. E eu ia fazer a matança. De uma história que eu montei. E ela [Theresinha Jansen, a dona do boi] estava avisando para todo mundo que o boi ia fazer o auto. Estava sendo divulgado que ia ter a representação do auto. Tinha as televisões, os pesquisadores, uma porção de gente lá com as máquinas, gravador, com as câmeras para gravar. E tu estava lá também. Então eu disse que não. Que eu ia fazer a matança, mas não podia ninguém gravar. Só tu. Aquela gente toda teve que baixar as máquinas para só olhar a matança. Então eu fazia a matança, a história todinha. E tu gravava, anotava tudo. E, depois, tu levava, arrumava tudo no computador, assim mesmo do jeito que tu faz. No dia seguinte, eu ia lá te encontrar no hotel onde tu estava, tu levava aqueles papéis tudinho, e nós ia dali para o cartório. Para registrar aquela matança. Como patrimônio cultural do bumba-boi do Maranhão, do sotaque de zabumba, de Guimarães. Mas interpretado por mim! Não é dizendo que é minha, entendeu? É patrimônio do bumba-boi do sotaque de zabumba, de Guimarães, do Maranhão, interpretado por mim. E aí, quando alguém viesse dizer que é dono daquela história, já estava lá registrado. É isso que eu quero. E tu vai ter que me ajudar. [em tom de brincadeira] Senão eu vou te botar na cadeia... (CARVALHO, 2004, p. 87).

As situações são muito distintas, mas ambas explicitam o desafio que a questão da propriedade intelectual nas criações do folclore e da cultura popular representa para as políticas públicas na área do patrimônio cultural de natureza imaterial. Na prática, os institutos de patrimonialização revelam dificuldades de reconhecer e lidar com a dimensão dos direitos autorais dos chamados detentores dos bens culturais, muito embora assumam, em tese, os princípios de defesa da autonomia dos mesmos em relação às decisões sobre a própria cultura e de respeito aos seus direitos da propriedade intelectual.

25 Os conflitos estiveram relacionados, sobretudo, a dificuldades da passagem do registro oral ao escrito. 
Uma das razões dessas dificuldades deve estar relacionada à natureza das criações intelectuais no campo do folclore e da cultura popular, que até o momento têm atraído a maior parte dos investimentos estatais voltados para o patrimônio cultural imaterial no Brasil. Algumas reflexões de Jakobson (1973) que, no caso de Betinho, foram bastante sugestivas, talvez ajudem também a esclarecer acerca das formas específicas de criação envolvidas no referido campo.

Comparando o autor/intérprete de obras folclóricas ao falante que sorve do conjunto estruturado de convenções da língua (langue) os elementos com os quais realiza, no ato particular da fala (parole), a faculdade da linguagem, Jakobson sustenta que a obra folclórica é criação coletiva na medida em que pressupõe um grupo que a aceite e sancione.

\footnotetext{
No folclore, a relação entre a obra de arte e sua objetivação, ou seja, as variantes dessa obra de arte interpretada por pessoas diferentes, é em tudo análoga à relação entre língua e fala. Como a língua, a obra folclórica é extrapessoal e tem apenas uma existência potencial; não passa de um conjunto complexo de determinadas normas, impulsões, um pano de fundo da tradição, sobre o qual agem os intérpretes, por meio de embelezamentos da criação individual, como o fazem os produtores da fala em relação à língua" (JAKOBSON, 1973, p. 63-64, tradução livre).
}

Ressalta-se que, ao contrário das perspectivas românticas que veem nas criações folclóricas e populares características de primitivismo, comunialismo e purismo, como demonstra Burke (1989), a tese do autor não postula anonimato ou espontaneidade nesse campo particular de criação. Desse modo, fornece bases teóricas para a elaboração de formulações mais atentas às especificidades que a noção de autoria pode assumir, e que poderiam ser úteis na abordagem da questão dos direitos de propriedade intelectual no âmbito dos institutos de patrimônio.

O conjunto de experiências que envolveu a produção do CD do Çairé, por sua vez, atesta a falibilidade dos instrumentos usuais que autorizam inventários e outras ações de patrimonialização. Atados a perspectivas jurídicas que visam, sobretudo, à garantia de direitos institucionais, desconsideram expectativas de direitos dos indivíduos e grupos que, com sorte, os próprios processos de patrimonialização estimulam.

\section{Referências}

BELAS, Carla Arouca. A propriedade intelectual no âmbito dos direitos difusos. In: TEIXEIRA, João Gabriel; GARCIA, Marcus Vinicius C.; GUSMÃO, Rita. (Orgs.). Patrimônio imaterial, performance cultural e (re) tradicionalização. Brasília: ICS-UnB, 2004.

BOYER, Véronique. Fronteiras da nação: religião, política e ancestralidade. 26 ${ }^{\mathrm{a}}$ Reunião Brasileira de Antropologia. Porto Seguro, 1-4 jun. 2008.

BRAGA, Sérgio Ivan Gil. Os Bois Bumbás de Parintins. Rio de Janeiro: Funarte; Manaus: Editora Universidade do Amazonas, 2002.

Festas religiosas e populares na Amazônia: algumas considerações sobre cultura popular. In: BRAGA, Sergio I. G. (Org.). Cultura popular, patrimônio imaterial e cidades. Manaus: Universidade Federal do Amazonas, 2007. 
BURKE, Peter. Cultura popular na idade moderna. Europa, 1500-1800. São Paulo: Companhia das Letras, 1989. CANDIDO, Antonio. Cururu. Remate de Males, Campinas, dez. 2012. Disponível em: <https://periodicos.sbu. unicamp.br/ojs/index.php/remate/article/view/8635987/3696>. Acesso em: 12 ago. 2018.

CARVALHO, José Jorge de. Metamorfoses das tradições performáticas afro-brasileiras: de patrimônio cultural à indústria de entretenimento. In: LONDRES, Cecília et al. Celebrações e saberes da cultura popular: pesquisa, inventário, crítica, perspectivas. Rio de Janeiro: Funarte, Iphan, CNFCP, 2004. (Encontros e Estudos, n. 5).

.'spetacularização' e 'canibalização' das culturas populares na América Latina. Revista Anthropológicas, v. 21, n. 1, p. 39-76, 2010.

CARVALHO, Luciana Gonçalves de. O desejo de Betinho e o decreto do presidente ou a questão da autoria no bumba-meu-boi do Maranhão e as políticas para o patrimônio imaterial no Brasil. In: LONDRES, Cecília et al. Celebrações e saberes da cultura popular: pesquisa, inventário, crítica, perspectivas. Rio de Janeiro: Funarte, IPHAN, CNFCP, 2004. (Série Encontros e Estudos, n. 5).

Tradições devotas, lúdicas inovações: o Sairé em múltiplas versões. Sociologia e Antropologia, Rio de Janeiro, v. 6, n. 1, p. 237-259, abr., 2016a.

(Coord.) Festa do Çairé de Alter do Chão. Santarém: UFOPA, 2016 b.

CAVALCANTI, Maria Laura Viveiros de Castro. O Boi-Bumbá de Parintins, Amazonas: breve história e etnografia da festa. Hist. cienc. saúde-Manguinhos, Rio de Janeiro , v. 6, p. 1019-1046, set. 2000. Disponível em: < http:// www.scielo.br/scielo.php?script=sci_arttext\&pid=S0104-59702000000500012> Acesso em: 10 jun. 2018.

COSTA, Maria Augusta Freitas. Turismo e patrimônio cultural: a Festa do Sairé em tempos de mudança cultural. In: CARVALHO, Luciana (Org.). Patrimônio cultural e direitos culturais na Amazônia: experiências de pesquisa e gestão. Santarém: Ufopa, 2013.

FERREIRA, Edilberto. O berço do Çairé. Santarém: Edição do Autor, Editora Valer, 2008.

FERREIRA, Gicele Brito. A ressignificação das relações comunitárias e a produção simbólica na mercantilização do Çairé. 2005. 178f. Dissertação (Mestrado em Serviço Social) - Centro Socioeconômico, Programa de Pós-Graduação em Serviço Social, Universidade Federal do Pará, Belém, 2005.

FIGUEIRA, Claudia Laurido. Festa popular na Amazônia: Sairé, a reinvenção da tradição em Alter do Chão (1973 a 1997). 2014. 201f. Dissertação (Mestrado em História Social) -- Programa de Pós-Graduação em História, Pontifícia Universidade Católica, São Paulo, 2014.

GLUCKMAN, Max. Análise de uma situação social na Zululândia moderna. In: FELDMAN-BIANCO, Bela. Antropologia das sociedades contemporâneas. São Paulo: Editora UNESP, 2010.

IPHAN. Manual de Aplicação do Inventário Nacional de Referências Culturais. Brasília: Departamento de Identificação e Documentação/Iphan/MinC, 2000.

Instrução Normativa no 001, de 2 de março de 2009. Dispõe sobre as condições de autorização de uso do Inventário Nacional de Referências Culturais (INRC). Disponível em: http://portal.iphan.gov.br/uploads/ckfinder/ arquivos/Instrucao_Normativa_001_2009(2).pdf. Acesso em: 9 jan 2019.

IPHAN; UFOPA. Minuta do Termo de Gestão Compartilhada da obra musical CD de músicas tradicionais da festa do Sairé, 2014.

JAKOBSON, R. Le folklore, forme spécifique de création. Questions de poétique. Paris: Editions du Seuil, 1973. LIMA, Nair Santos. A travessia do Sairé: estudos para o desenvolvimento de um olhar ecossistêmico e semiótico da comunicação. 2013. 146f. Dissertação (Mestrado em Ciências da Comunicação) - Programa de Pós-Graduação em Ciências da Comunicação da Universidade Federal do Amazonas, Manaus, 2013.

MALINOWSKI, Bronislaw. Os Argonautas do Pacífico Ocidental. São Paulo: Abril Cultural, 1978.

MASCARENHAS, Rosana Farias. Análise de uma situação social, envolvendo narrativa e memoria social: a 
experiência do CD do Conjunto Espanta Cão. Trabalho apresentado no âmbito do INRC-Sairé -- Universidade Federal do Oeste do Pará, Santarém, 2015.

MORAIS, Sara S.; RAMASSOTE, Rodrigo; ARANTES NETO, Antônio A. Trajetória e desafios do Inventário Nacional de Referências Culturais (INRC): Entrevista com Antonio Arantes. Revista CPC, n. 20, p. 221-260, dez. 2015. Disponível em: http://www.revistas.usp.br/cpc/article/view/104911. Acesso em: 12 ago. 2018.

NOGUEIRA, Wilson. Festas amazônicas: boi-bumbá, ciranda e sairé. Manaus: Valer, 2008.

A espetacularização do imaginário amazônico no boi-bumbá de Parintins. 2013. 244 f. Tese (Doutorado em Sociedade e Cultura na Amazônia) - Universidade Federal do Amazonas, Manaus, 2013.

PEREIRA, Nunes. O Sairé e o Marabaixo: tradições da Amazônia. Recife: FUNDAJ; Massangana, 1989.

RODRIGUES, Carmem Izabel. Festividades mestiças na Amazônia. História revista, v. 14, n. 1, 2009.

RODRIGUES, João Barbosa. Poranduba amazonense, ou kochiyma-uara porandub, 1872-1887. Rio de Janeiro: Typ. de G. Leuzinger \& Filhos, 1890. Disponível em: http://biblio.etnolinguistica.org/rodrigues_1890_poranduba Acesso em: 10 jun. 2018.

TURNER, Victor. Dramas, fields and metaphors: symbolic action in human society. Cornell University Press, 1974. UFOPA. Relato da reunião com o grupo de foliões e músicos do Espanta-Cão. Santarém, 11 ago. 2012.

. Terceiro Relatório Parcial de Atividades do Inventário de Referências Culturais do Sairé. Santarém, jan./ jun. 2013.

VERÍSSIMO, José. As populações indígenas e mestiças na Amazônia. Revista Trimensal do Instituto Historico e Geographico Brazileiro, Rio de Janeiro, Tomo L, Parte Primeira, p. 295-390, 1887. Disponível em: http://biblio. etnolinguistica.org/verissimo_1887_populacoes. Acesso em: 29 jan. 2018.

Recebido em: 07/07/2018

Aceito em: 20/08/2018 